Vitreous

\title{
management in penetrating trauma: primary repair and secondary intervention
}

\begin{abstract}
Ocular trauma involving the vitreous produces a very wide range of pathology, the treatment of which can confuse. In the past, the prognosis for vision following such injuries was poor. Modern closed intraocular surgical techniques have transformed the management of penetrating trauma and allowed salvage of vision in many previously hopeless cases. However, many controversies remain, including the timing of surgical intervention, the use of encircling buckles, and the type of internal tamponade. This article will discuss those controversies, and make some practical recommendations for the management of penetrating and perforating trauma involving the vitreous.
\end{abstract}

Eye (2008) 22, 1366-1369; doi:10.1038/eye.2008.74; published online 18 April 2008

Keywords: trauma; penetrating; perforating; choroidal haemorrhage; primary repair

Vitreoretinal Surgical Unit, Moorfields Eye Hospital, London, UK

Correspondence: GW Aylward,

Vitreoretinal Surgical Unit, Moorfields Eye Hospital, City Road,

London EC1V 2PD, UK.

Tel: + 0207566 2039;

Fax: +02075662039.

E-mail: bill.aylward@

moorfields.nhs.uk

Received: 22 January 2008 Accepted in revised form: 22 January 2008

Published online: 18 April 2008

\section{Introduction}

This article will focus on some of the current controversies regarding the treatment of penetrating trauma, particularly with respect to the management of the vitreous. Trauma can result in a highly diverse range of ophthalmic injury, which can make the comparison between individual cases difficult. Hence, the terminology used in this article is that proposed by the International Society of Ocular Trauma. ${ }^{1}$ On the basis of this classification, I will discuss the management of both penetrating (single entry wound) and perforating trauma (entry and exit wound), but will exclude discussion of intraocular foreign bodies.
Together, penetrating and perforating trauma account for about $40 \%$ of serious eye injuries, ${ }^{2}$ though thankfully that they are both relatively rare. However, as described in a recent article, ${ }^{3}$ we are approaching the 90th anniversary of one of the biggest collection of such injuries arising from a single incident. A ship carrying wartime ordnance caught fire after a minor collision.

After $20 \mathrm{~min}$, just as large crowds had formed, and people had gathered in windows to watch, the ship exploded with energy equivalent to $3 \mathrm{kt}$ of TNT. An area $2.5 \mathrm{~km}$ in diameter was flattened, and not a single window remained unbroken in the city. In addition to large loss of life, there were 592 patients with eye injuries, mainly from flying glass. Ophthalmologists carried out 249 enucleations, which was consistent with agreed management at the time. Since then, the introduction of pars plana vitrectomy ${ }^{4}$ and subsequent improvements in associated instrumentation has increased the treatment options for trauma cases. At the same time, improvements in our understanding of pathological mechanisms have resulted from the study of animal models. These two factors have allowed many eyes that would previously have been enucleated to be saved.

\section{Pathology}

We owe much of our current understanding of the pathological mechanisms following trauma to the work of Cleary and Ryan. ${ }^{5}$ They

developed a reproducible animal model, which gave innumerable insights into the

pathophysiology, as well as allowing studies of intervention. A single pars plana wound was created in a primate eye, with prolapse of the vitreous, followed by closure of the wound and intravitreal injection of autologous blood. 
Subsequent histological studies showed the importance of blood in creating a posterior vitreous detachment (PVD) after about a week. Proliferation of cells on the surface of the retina and vitreous subsequently led to traction retinal detachment, which usually occurred after 6 weeks. These findings were consistent with histological studies of enucleated human eyes after trauma. ${ }^{6}$ Other animal studies of perforating wounds also indicated the tendency of proliferation to occur within the vitreous along the track of the wound. Subsequent contraction led to retinal detachment. ${ }^{7}$ A clinical example of this phenomenon is illustrated in Figure 1.

Given the importance of the vitreous in the generation of traction retinal detachment, it was a logical step to find out whether removal of the vitreous could reduce the risk. Cleary and Ryan $^{8}$ showed that vitrectomy between 1 and 14 days after injury in their animal model
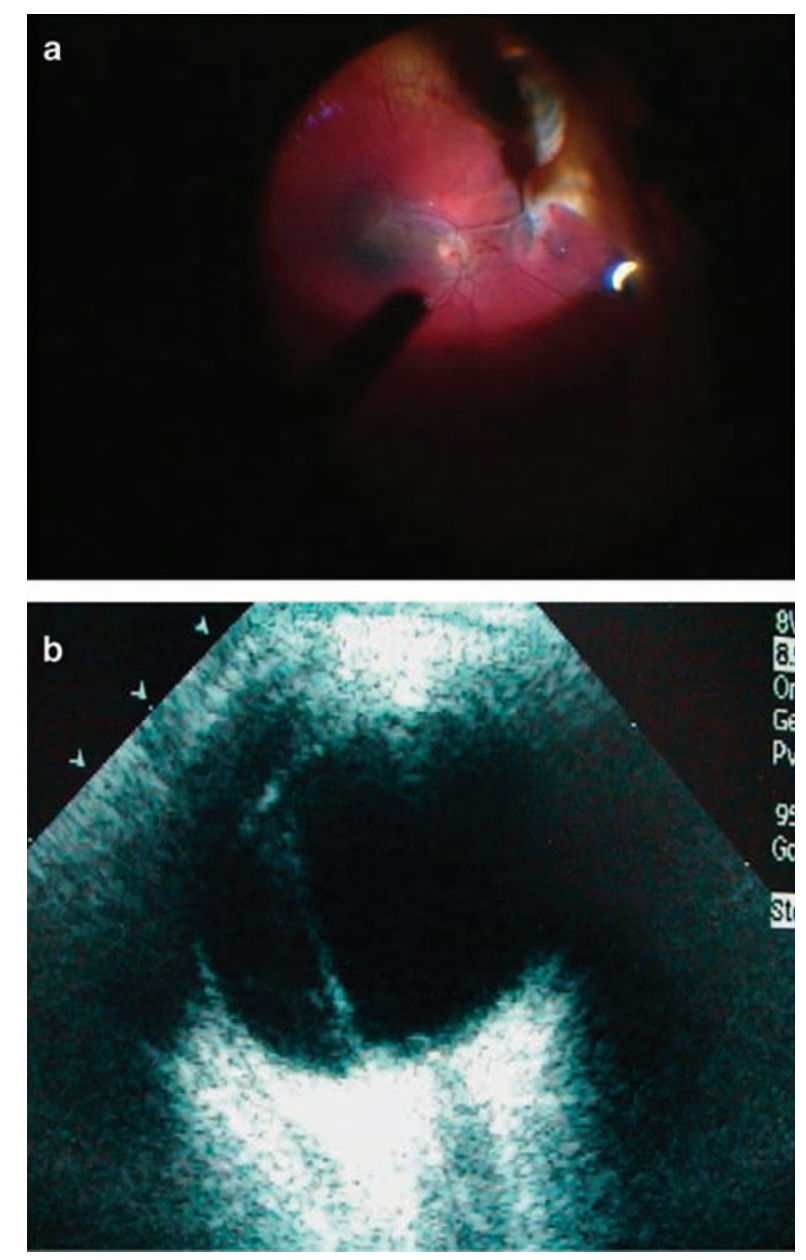

Figure 1 (a) Image captured during surgery showing a contracted firbrous band along the track of a perforating wound in the left eye of a 10-year-old child. The band is brown in colour and stretches from the top right of the frame to the exit wound at the right of the optic disc. (b) Preoperative ultrasounds showing vitreous fibrosis along the track of perforating wound. significantly reduced the risk of traction retinal detachment.

\section{Primary repair}

Every effort should be made to repair and preserve the globe if at all possible. In the past, fear of sympathetic ophthalmitis encouraged primary enucleation, particularly for eyes with no perception of light (NPL). ${ }^{3}$ However, with modern vitreoretinal techniques, many of these eyes can be saved. In one study of 340 cases with an initial acuity of NPL from the US eye injuries' register, $13 \%$ improved and $15 \%$ of these achieved a final vision of $5 / 200$ or better. ${ }^{2}$

Conventionally, a primary repair is carried out as soon as possible after the injury. Definitive vitreoretinal management is then deferred. This two-stage management usually arises because vitreoretinal expertise (in assessment and treatment) is not immediately available. Certainly, it is important to avoid undue delay in closing the globe, but if the patient presents to a vitreoretinal unit, it may sometimes be appropriate to carry out definitive vitrectomy surgery at the same sitting. However, there are legitimate concerns about the best timing of vitrectomy, and these concerns will be discussed later in this article.

The aim of primary repair is to restore integrity of the globe, to allow resolution of hypotony, and to repair the barrier against infection. The full extent of the wound should be identified, if necessary by reflecting the conjunctiva and clearing any surface haemorrhage. At this stage, any obvious foreign bodies should be removed. Prolapsed uveal tissue should be replaced unless obviously necrotic or contaminated. Nonabsorbable sutures are then used to repair the cornea and sclera. 10/0 nylon is usually used for the cornea and either $10 / 0$ or $9 / 0$ nylon for the sclera. Any prolapsed vitreous should be identified and removed. A vitreous cutter passed through the limbus or through part of the wound can be used to relieve anterior vitreous incarceration from the inside. Involvement of the lens is a significant risk factor for endophthalmitis, ${ }^{9}$ so if the lens capsule is breached, a primary lensectomy should be performed using a vitreous cutter and an anterior segment infusion. A rim of anterior capsule can be retained for secondary placement of a sulcus-based intraocular lens. For perforating lesions, it is rarely necessary to close the exit wound. This is often selfsealing and does not represent a portal for infection. In addition, the manipulation of the globe required to gain access to it may increase the risk of haemorrhage or prolapse of uveal tissue. 


\section{Secondary management}

Once the primary repair is complete, the opportunity arises to treat any associated inflammation and to carry out a detailed assessment of visual acuity and ocular damage before further surgical intervention. Ultrasonography is a vital investigation and will reveal the extent of injury to the posterior segment, the presence of choroidal haemorrhage, and can often detect intraocular foreign bodies (IOFB). If there is doubt about the presence of an IOFB, then supplementary plain radiography or CT scanning can be helpful.

Controversy remains about the best timing of secondary intervention. Most surgeons agree that vitrectomy should be undertaken before 14 days, as animal studies indicate that the risk of traction retinal detachment increases after that. ${ }^{5}$ Furthermore, a comparative trial in an animal model showed that vitrectomy within 14 days was associated with a clear reduction of retinal detachment risk. ${ }^{8}$ However, there are two broad schools of thought as to when within that window treatment should be applied. The 'early school' claim that vitrectomy within 3 days reduces the opportunity for inflammation to occur, and for epiretinal tissue to develop. ${ }^{10}$ The 'late school' point out that a PVD has often occurred spontaneously by 10 days which makes vitrectomy easier and safer. ${ }^{11}$ In addition, they point to a possible increased risk of severe haemorrhage, if operating within a few days of the injury. ${ }^{12}$ There are no clinical studies, which address the question of timing definitively and this is likely to remain a controversial issue for some time.

The aim of vitrectomy surgery should be to remove as much vitreous as possible, so as to reduce any potential scaffold for inflammation and epiretinal membrane formation. The generation of a PVD is vital in this regard, though can be difficult to carry out, particularly due to the fact that the most patients in this group are young. Once a core vitrectomy has been carried out, the aperture of the cutter should be placed on the nasal side of the disc, and using full suction without cutting, the posterior hyaloid is engaged in the aperture. Small side-to-side movements of the cutter are usually sufficient to generate a PVD, as indicated by the appearance of a Weiss ring. Once it is initiated, the PVD can be extended gently into the periphery as far as the vitreous base. If aspiration alone is insufficient, ILM forceps can be used to grasp the posterior hyaloid near the disc and apply direct traction. However, care must be taken to ensure that the nerve fibre layer is not engaged in the forceps.

The vitreous base should be trimmed, paying particular attention to removing any haemorrhage. There should be complete clearance around the entry and exit wounds to minimise incarceration. The continuing presence of vitreous incarceration is a risk factor for traction retinal detachment as well as for giant retinal tear (GRT). In one study of traumatic GRTs, delayed presentation was associated with the presence of incarceration from a penetrating wound and a later PVD. ${ }^{13}$ If the lens has been involved, any remaining soft lens matter should be aspirated and capsular remnants tidied up. Choroidal haemorrhage often drains through the sclerostomies, particularly if there has been sufficient time for lysis to occur. However, in the presence of significant choroidal haemorrhage, it may be necessary to perform a posterior sclerotomy.

The placement of an encircling scleral buckle has been advocated on the basis that complete removal of the vitreous base is never possible and the remaining tissue may contract leading to traction retinal detachment or retinal breaks, particularly in the presence of haemorrhage. The rationale of encirclement is to reduce the circumference of the vitreous base and thereby relieve traction on the peripheral retina. Therefore, an ora-occlusive buckle should be used rather than an equatorial encircling band. There are no randomized trials to support the use of scleral buckling in trauma, although one non-randomised study showed a reduction in retinal detachment in the buckling group, which did not achieve statistical significance. ${ }^{14}$

Once the major surgical goals have been achieved, a decision should be made whether to insert tamponade, and if so, which type. Tamponade is indicated in the presence of retinal breaks or if there is uncertainty about the absence of breaks. If the presence of blood or scar tissue precludes a thorough examination of the peripheral retina, then tamponade should be considered. However, to be effective in the long term, this should be accompanied by the application of retinopexy around the suspicious area. If there is significant choroidal haemorrhage or a high risk of development or proliferative vitreoretinopathy (PVR), then the use of silicone oil should be considered. Silicone oil will reduce the risk of further choroidal haemorrhage, as well as limit the extent of later retinal detachment should this occur.

A major complication following trauma and secondary intervention is the subsequent development of PVR. The incidence is considerably higher than that following non-traumatic rhegmatogenous retinal detachment. ${ }^{15}$ There has been considerable interest in the use of adjunctive therapy to reduce the risk of PVR. Recently, a study of eyes undergoing vitrectomy for retinal detachment at high risk of PVR indicated that the risk could be cut in half, if 5-fluoro-uracil and low-molecularweight heparin were infused during the vitrectomy. ${ }^{16}$ However, this beneficial effect was not found in patients with established PVR. ${ }^{17}$ To the best of our knowledge, no 
study has been carried out to investigate the use of adjunctive therapy in trauma cases to date.

\section{Conclusion}

The management of penetrating ocular trauma has improved considerably over the last three decades. However, many questions remain about the optimal management. Every trauma case is different, and a flexible approach based on knowledge of the pathological processes, the vitreoretinal skills available, and the details of the individual case is recommended.

\section{References}

1 Kuhn F, Morris R, Witherspoon CD, Heimann K, Jeffers JB, Treister G. A standardized classification of ocular trauma. Ophthalmology 1996; 103: 240-243.

2 May DR, Kuhn FP, Morris RE, Witherspoon CD, Danis RP, Matthews GP et al. The epidemiology of serious eye injuries from the United States Eye Injury Registry. Graefe's Arch Clin Exp Ophthalmol 2000; 238: 153-157.

3 McAlister CN, Murray TJ, Lakosha H, Maxner CE. The Halifax disaster (1917): eye injuries and their care. $\mathrm{Br} J$ Ophthalmol 2007; 91: 832-835.

4 Machemer R, Buettner H, Norton EW, Parel JM. Vitrectomy: a pars plana approach. Trans Am Acad Ophthalmol Otolaryngol 1971; 75: 813-820.

5 Cleary PE, Ryan SJ. Method of production and natural history of experimental posterior penetrating eye injury in the monkey. Am J Ophthalmol 1979; 88: 212-220.

6 Winthrop SR, Cleary PE, Minckler DS, Ryan SJ. Penetrating eye injuries: a histopathological review. $\mathrm{Br} J$ Ophthalmol 1980; 64: 809-817.

7 Topping TM, Abrams GW, Machemer R. Experimental double perforating injury of the posterior segment in rabbit eyes. Arch Ophthalmol 1979; 97: 735-742.
8 Cleary PE, Ryan SJ. Vitrectomy in penetrating eye injury: Results of a controlled trial in the rhesus monkey. Arch Ophthalmol 1981; 99: 287-292.

9 Thompson WS, Rubsamen PE, Flynn Jr HW, Schiffman J, Cousins SW. Endophthalmitis after penetrating trauma. Risk factors and visual acuity outcomes. Ophthalmology 1995; 102: 1696-1701.

10 Coleman DJ. Early vitrectomy in the management of the severely traumatized eye. Am J Ophthalmol 1982; 93: 543-551.

11 Ryan SJ. Guidelines in the management of penetrating ocular trauma with emphasis on the role of timing of pars plana vitrectomy. Int Ophthalmol 1979; 1: 105-108.

12 Cupples HP, Whitmore PV, Wertz III FD, Mazur DO. Ocular trauma treated by vitreous surgery. Retina 1983; 3: 103-107.

13 Aylward GW, Cooling RJ, Gregor ZG. Trauma-induced retinal detachment associated with GRTs. Retina 1993; 13: 136-141.

14 Arroyo JG, Postel EA, Stone T, McCuen BW, Egan KM. A matched study of primary scleral buckle placement during repair of posterior segment open globe injuries. $\mathrm{Br} J$ Ophthalmol 2003; 87: 75-78.

15 Cardillo JA, Stout JT, LaBree L, Azen SP, Omphroy L, Cui JZ et al. Post-traumatic proliferative vitreoretinopathy: the epidemiological profile, onset, risk factors, and visual outcome. Ophthalmology 1997; 104: 1166-1173.

16 Asaria RHY, Kon CH, Bunce C, Charteris DG, Wong D, Khaw PTet al. Adjuvant 5-fluorouracil and heparin prevents proliferative vitreoretinopathy: results from a randomised double blind controlled clinical trial. Ophthalmology 2001; 108: 1179-1183.

17 Charteris DG, Aylward GW, Wong D, Groenewald C, Asaria RH, Bunce C, PVR Study Group. A randomized controlled trial of combined 5-fluorouracil and lowmolecular-weight heparin in management of established proliferative vitreoretinopathy. Ophthalmology 2004; 111: 2240-2245. 